Editorial

\title{
Synthesis, Characterization, and Applications of Polymer Nanocomposites
}

\author{
Emad M. Masoud $\mathbb{D}^{1,2}$ Laijun Liu $\mathbb{D}^{,}{ }^{3}$ and Biaolin Peng $\mathbb{D}^{4}$ \\ ${ }^{1}$ Chemistry Department, Faculty of Science, Islamic University of Madinah, 20012 Madinah, Saudi Arabia \\ ${ }^{2}$ Chemistry Department, Faculty of Science, Benha University, 13518 Benha, Egypt \\ ${ }^{3}$ College of Materials Science and Engineering, Guilin University of Technology, Guilin 541004, China \\ ${ }^{4}$ Guangxi Key Laboratory for Relativistic Astrophysics, School of Physical Science \& Technology, Guangxi University, \\ Nanning 530004, China \\ Correspondence should be addressed to Emad M. Masoud; emad.youssef@fsc.bu.edu.eg, Laijun Liu; ljliu2@163.com, \\ and Biaolin Peng; pengbl8@126.com
}

Received 28 November 2019; Accepted 29 November 2019; Published 6 January 2020

Copyright (c) 2020 Emad M. Masoud et al. This is an open access article distributed under the Creative Commons Attribution License, which permits unrestricted use, distribution, and reproduction in any medium, provided the original work is properly cited.

Polymer nanocomposites can be defined as materials in which nanoscopic inorganic particles, in at least one dimension, are dispersed in an organic polymer matrix to improve its performance properties. Polymer nanocomposites represent a new alternative to conventional filled polymers. Because of their size, the filler dispersion that nanocomposites exhibit markedly improves their properties when compared to pure polymers [1-7] or their traditional composites. These properties include increased tensile strength, conductivity and thermal stability as well as decreased flammability.

This special issue focuses on the synthesis, characterization, electrical properties, and applications of polymer nanocomposites such as sun protection, resistive switching device, wastewater treatment, and biosensors.

For the topics of synthesis and characterization of polymer nanocomposites, hybrid composites can be used as effective protective materials against ultraviolet rays since they have a low transmission and high reflection. Also, the result proves that hybrid composites, $\mathrm{Nia} / \mathrm{ZnO}$, are an excellent material for ultraviolet ray protection.

For the topics of the structure and electrical properties of polymer nanocomposites, WORM/volatile static random access memory (SRAM) conversion was triggered by the composite of the oxadiazole small molecule. FTO/PMMA/Ag device possesses nonvolatile WORM memory behavior, while the FTO/PMMA+oxadiazole/Ag device shows vastly different volatile SRAM feature. The FTO/PMMA/Ag and FTO/PMMA+oxadiazole/Ag memory devices both exhibit high ON/OFF ratio nearly $10^{4}$. The results manifest the significance of oxadiazole small molecule to the memory effects and will arouse the interest of a scholar to research small molecule composite for the expecting memory devices. Broadband dielectric spectra of epoxy resin composites are filled with $\mathrm{WS}_{2}$ nanotubes in wide temperature range and demonstrate for the first time influence of $\mathrm{WS}_{2}$ nanotubes on the electrical properties of composites. Electrical and thermal behavior of high-density polyethylene (HDPE) polymer with alumina nanofillers was reported in this issue. This is significant because studies related to environment pollution have shown that these nonbiodegradable materials cause global warming in all over the world. A novel method to control the localization of APP and CNTs in blends was proposed. Excellent flame retardancy was exhibited only in blends with localization of APP in the PA6 phase and CNTs in the LLDPE phase. A kind of nanocomposite paper was obtained by evaporation-induced self-assembly of a mixture of sisal cellulose nanofibers (CNF) and polyethylene glycol (PEG) as the matrix and citric acid (CA) as the crosslinking agent. The CNF/PEG/CA paper exhibited good water swelling 
resistance which could be controlled by changing the concentration of CA. In addition, this nanocomposite paper exhibited good mechanical properties and water-induced shape memory performance.

For the topics of application of polymer nanocomposites in water treatments and biosensors, magnetite-alginate nanoparticles (M-AlgNPs) were synthesized via the coprecipitation method. The M-AlgNPs were applied as a green adsorbent for removing $\mathrm{Ni}^{2+}$ and $\mathrm{Co}^{2+}$ from wastewater. Nanocomposites IL-RGO/ZIF-8 (ionic liquid functionalized reduced graphene oxide/zeolitic imidazolate framework-8) were prepared by in situ growth of ZIF- 8 on a small quantity of IL-RGO temple. The prepared composites were coated on a glass carbon electrode (GCE) as a sensor for detecting dopamine (DA). The electrochemical performance for DA detection is enhanced owing to the synergistic effect of ZIF8 with a large surface area and order porous structure and IL-RGO with high electron conductivity. A high-sensitivity sensor for DA can be obtained. The IL-RGO/ZIF-8-modified electrode exhibits good electrocatalytic activity and electroconductive properties towards dopamine (DA) which were investigated by cyclic voltammetry and differential pulse voltammetry (DPV). The sensor was shown to provide satisfactory stability for the determination of DA. Rituximab/MTX-PEG-PLL-PLGA nanoparticles were designed and further crosslinked transferrin-receptor-monoantibody (TfRmAb). It had excellent physical properties and longtermed sustained drug release efficiency. The nanoparticleloaded system can precisely and efficiently transport the rituximab and methotrexate (MTX) drug into SU-DHL-4 cells, a typical kind of B lymphocytes, resulting in the significant increase of the cell apoptosis in the SU-DHL-4 cells. The novel multifunctional drug-loaded nanoparticles are persistently and precisely targeted to SU-DHL-4 cells, which enhanced the anticancer efficiency in B lymphocytes.

\section{Conflicts of Interest}

The authors declare that there is no conflict of interest regarding the publication of this article.

\section{Acknowledgments}

We would like to thank the editorial board who provided us with the chance to manage this special issue. The professional support team and user-friendly system make our editorial work with ease. Special thanks should be given to all authors who contributed their papers including those that have not been published in this special issue. All the participants have made it possible to have a very stimulating interchange of ideas. The acceptance rate of this special issue ( 11 out of 23 ) is less than $50 \%$, implying that all the submitted works are in high quality. We wish you all enjoy this quality-controlled special issue.

\section{References}

[1] A. A. ElBellihi, W. A. Bayoumy, E. M. Masoud, and M. A. Mousa, "Preparation, characterizations and conductivity of composite polymer electrolytes based on $\mathrm{PEO}-\mathrm{LiClO}_{4}$ and Nano ZnO filler," Bulletin of the Korean Chemical Society, vol. 33, no. 9, pp. 2949-2954, 2012.

[2] E. M. Masoud, A.-A. El-Bellihi, W. A. Bayoumy, and M. A. Mousa, "Organic-inorganic composite polymer electrolyte based on $\mathrm{PEO}-\mathrm{LiClO}_{4}$ and nano- $\mathrm{Al}_{2} \mathrm{O}_{3}$ filler for lithium polymer batteries: dielectric and transport properties," Journal of Alloys and Compounds, vol. 575, pp. 223-228, 2013.

[3] E. M. Masoud, A.-A. El-Bellihi, W. A. Bayoumy, and M. A. Mousa, "Effect of $\mathrm{LiAlO}_{2}$ nanoparticle filler concentration on the electrical properties of $\mathrm{PEO}-\mathrm{LiClO}_{4}$ composite," Materials Research Bulletin, vol. 48, no. 3, pp. 1148-1154, 2013.

[4] E. M. Masoud, "Nano lithium aluminate filler incorporating gel lithium triflate polymer composite: Preparation, characterization and application as an electrolyte in lithium ion batteries," Polymer Testing, vol. 56, pp. 65-73, 2016.

[5] E. M. Masoud, M. E. Hassan, S. E. Wahdaan, S. R. Elsayed, and S. A. Elsayed, "Gel P (VdF/HFP)/PVAc/lithium hexafluorophosphate composite electrolyte containing nano $\mathrm{ZnO}$ filler for lithium ion batteries application: effect of nano filler concentration on structure, thermal stability and transport properties," Polymer Testing, vol. 56, pp. 277-286, 2016.

[6] E. M. Masoud, A.-A. El-Bellihi, W. A. Bayoumy, and E. A. Mohamed, "Polymer composite containing nano magnesium oxide filler and lithiumtriflate salt: an efficient polymer electrolyte for lithium ion batteries application," Journal of Molecular Liquids, vol. 260, pp. 237-244, 2018.

[7] E. M. Masoud, "Montmorillonite incorporated polymethylmethacrylate matrix containing lithium trifluoromethanesulphonate (LTF) salt: thermally stable polymer nanocomposite electrolyte for lithium-ion batteries application," Ionics, vol. 25, no. 6, pp. 2645-2656, 2019. 


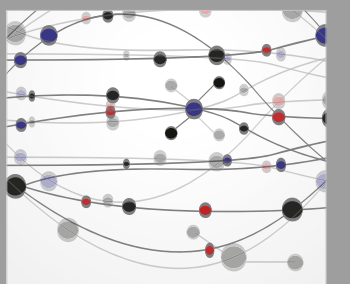

The Scientific World Journal
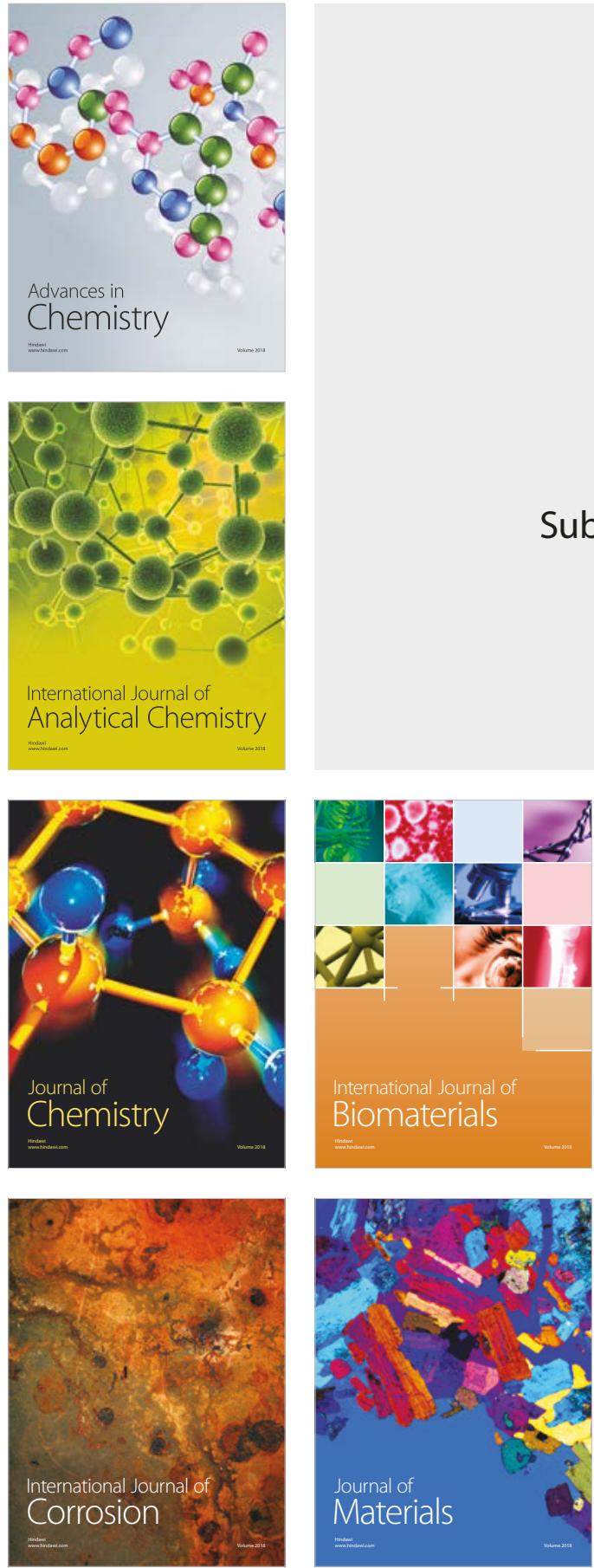

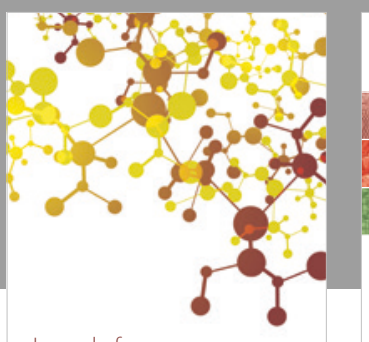

Journal of

Applied Chemistry
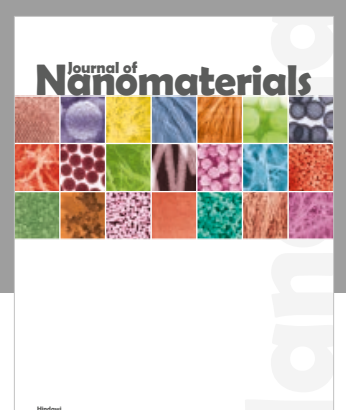

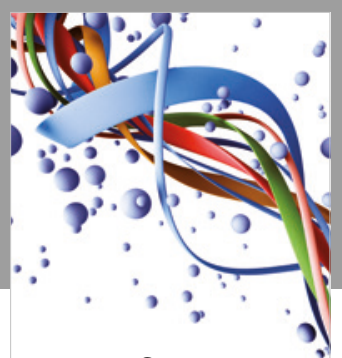

Scientifica

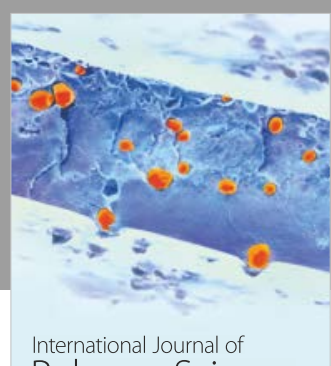

Polymer Science

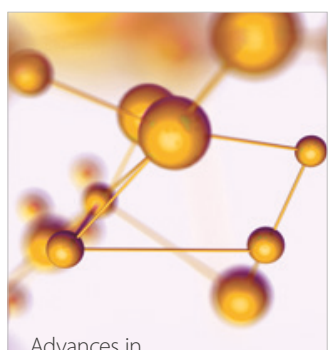

Physical Chemistry
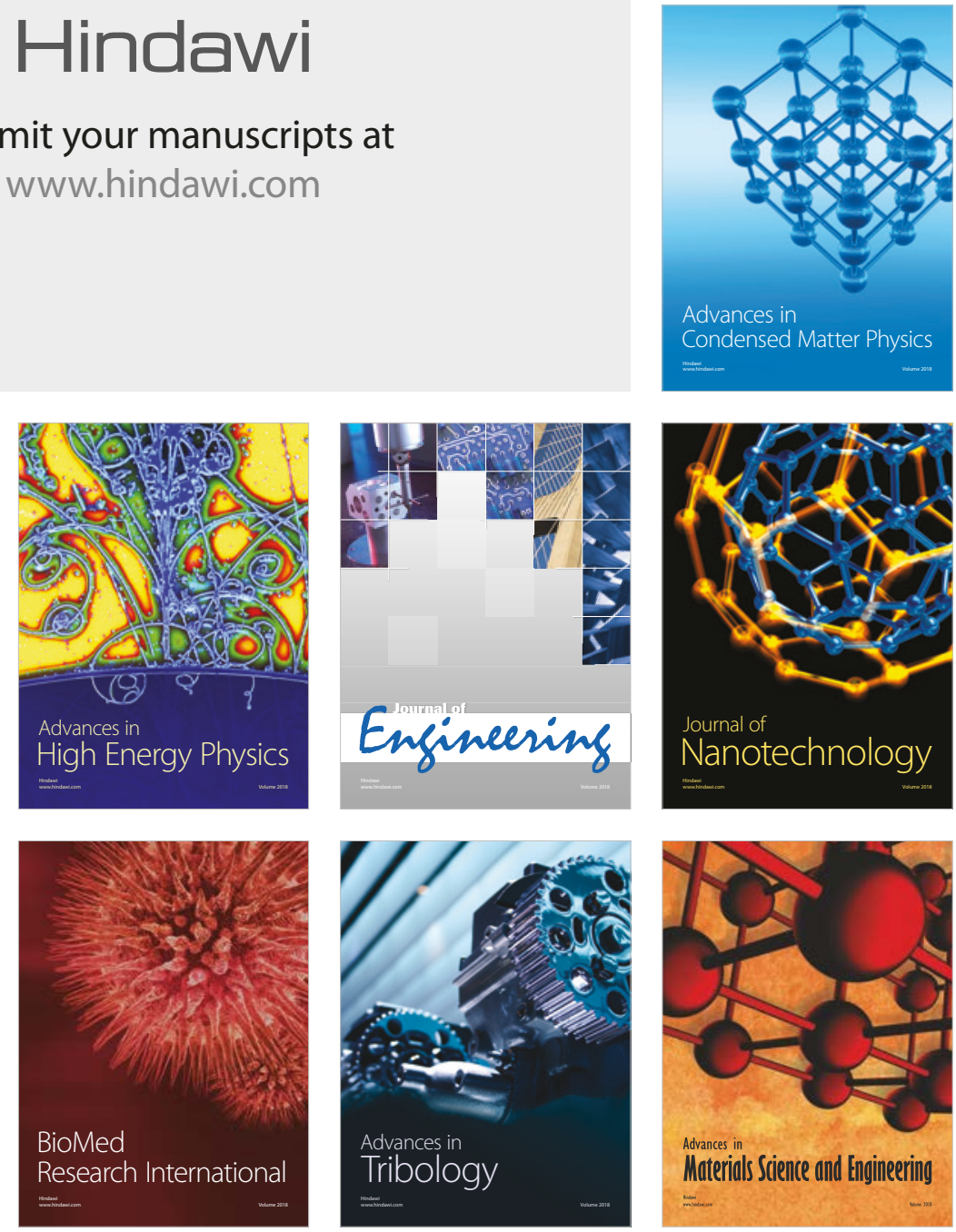